\title{
Managerialism nas instituições de ensino superior brasileiras
}

\author{
Managerialism in brazilian higher education instituitions
}

\author{
Thiago Coelho Soares ${ }^{1}$ \\ Maurício Andrade de Lima²
}

\begin{abstract}
Resumo
O objetivo deste artigo consiste em verificar, estatisticamente, se nas instituições de ensino superior(IES) privadas os indicadores de avaliação de desempenho organizacional possuem relevância diferente do que nas IES públicas, tentando identificar a existência do managerialism.Para alcançar o objetivo, optou-se por uma pesquisa quantitativa, com técnica de coleta de dados do tipo survey. Para a análise dos dados, utilizou-se a técnica estatística denominada teste t para grupos independentes, pois se testou a hipótese de pesquisa estatisticamente. Como resultado da pesquisa, destaca-se que: vinte por cento dos indicadores de origem na avaliação institucional do MEC não possuem diferença estatística entre IES públicas e privadas. Em quarenta e um porcento dos indicadores com origem em metodologias de avaliação de desempenho empresarial existiu diferença de percepção nos dois grupos. Como conclusão desta pesquisa observa-se a existência de managerialism nas IES brasileiras.
\end{abstract}

Palavras-chave: Managerialism; Instituições de Ensino Superior; Indicadores de desempenho.

\begin{abstract}
The purpose of this paper is to verify statistically whether private higher education institutions (IES) have organizational performance evaluation indicators that differ from those of public HEls. We were trying to identify the existence of managerialism. In order to reach the objective, a quantitative research was chosen, with a survey data collection technique. For the analysis of the data, we used the statistical technique called t-test for independent groups, since the research hypothesis was statistically tested. As a result of the research it is highlighted that twenty percent of the origin indicators in the institutional evaluation of the MEC do not have statistical difference between public and private HEls. Forty-one percent of the indicators that originated in business performance evaluation methodologies existed a difference of perception in both groups. As conclusion of this research it is observed the existence of managerialism in Brazilian HEls.
\end{abstract}

Keywords: Managerialism; Higher Education Institutions; Performance indicators.

\section{Introdução}

As instituições de educação superior(IES) privadas estão imersas em um ambiente externo competitivo e de constantes e grandes transformações. Como forma indispensável de sobrevivência em curto prazo e de garantir sua sobrevivência em longo prazo, as IES têm sido desafiadas em sua capacidade de responder a esse ambiente externo. A adoção de práticas de gestão, tais como o planejamento estratégico e avaliação de desempenho, têm sido cada vez mais crescentes. Porém, cabe ressaltar que a literatura ainda é escassa no que se refere a estudos mais aprofundados sobre essas práticas em IES, principalmente voltados à formação de estratégias e desempenho em organizações educacionais. As diferenças existentes entre empresas e instituições de educação superior possuem grandes implicações na prática da gestão destas últimas (MEYER JR.; PASCUCCI; MANGOLIN, 2012).

O cenário descrito anteriormente, quando associado à inexistência de uma teoria própria de administração universitária, promove, nas instituições de educação superior, utilização de ferramentas e modelos gerenciais

Doutor em Administração pela Universidade Federal de Santa Catarina (UFSC). Brasil. Afiliação: Universidade do Sul de Santa Catarina Unisul. Lattes: http://lattes.cnpq.br/6934371080590577 Email: thiago.soares@unisul.br

2 Doutor e professor do PPGA da Universidade do Sul de Santa Catarina (Unisul). Brasil. Afiliação: Unisul. Lattes: http://lattes.cnpq. br/6700505910643248 Email: mauricio.lima@unisul.br 
do setor empresarial. Consequentemente, existe uma tendência cada vez maior entre as instituições privadas de educação superior em se identificarem como "empresa"(MEYER JR.; PASCUCCI; MANGOLIN, 2012). Nesse sentido, a LDB (Lei de Diretrizes e Bases da Educação Nacional) é apontada como marco legal da reforma que foi colocada em curso na década de 1990, pela qual o Estado assume o controle e a gestão das políticas públicas. O Estado é o máximo gestor no que se refere à avaliação e ao controle das IES, mas é o mínimo no que se refere ao financiamento das IES públicas, liberando a oferta da educação superior para a iniciativa privada (CRUZ; PAULA, 2015; GOERGEN, 2010).

A incorporação de modelos de gestão empresarial nas práticas gerenciais tem se justificado. Esse fenômeno tem-se denominado managerialism. Orientada por princípios de racionalidade, e tendo como foco maior a produtividade e a busca de resultados econômico-financeiros, a prática de modelos empresariais, além de resultados limitados, tende a distanciar as IES de seus objetivos e de sua missão institucional: o papel social e o educacional. Para que as instituições de educação superior privadas possam responder aos desafios que lhes impõem um novo contexto econômico, social e tecnológico e se manterem atuantes num ambiente competitivo, torna-se necessário que tais organizações estejam dotadas de uma gestão eficaz. A gestão dessas organizações deve contribuir para a produção, aplicação e transmissão do conhecimento, tendo como principal beneficiário a própria sociedade, que as mantém e legitima (GEIGER, 1985; MEYER; ROWAN, 1977; MEYER JR.; PASCUCCI; MANGOLIN, 2012).

Na literatura, observam-se estudos sobre managerialism em IES (ADRIANO; RAMOS, 2015; ALMEIDA, 2012; BLASCHKE; FROST; HATTKE, 2014; BRUECKNER; HOLMES; PICK, 2017; KALFA; TAKSA, 2017; MEYER; MEYER JÚNIOR, 2013; MEYER JR.; PASCUCCI; MANGOLIN, 2012; ORR; ORR, 2016; PETERS, 2013; SANTIAGO; CARVALHO, 2012; VIEIRA; MENDONÇA NETO; ANTUNES, 2015; WILLNER, 2017), porém nenhum comprova a existência do managerialism estatisticamente.

O problema de pesquisa a ser tratado é: Existe managerialism nas IES brasileiras?Desta forma, o objetivo deste artigo é verificar, estatisticamente, se nas IES privadas os indicadores de avaliação de desempenho possuem relevância diferente do que nas IES públicas, tentando identificar a existência do managerialism. Assim, a hipótese a ser testada neste artigo é $\mathrm{HO}=\mathrm{A}$ percepção de dirigentes e integrantes das CPAs (Comissão Própria de Avaliação) de IES públicas e privadas é igual, ou seja, não existe managerialism.

$O$ artigo se justifica, em parte, pelos autores anteriormente citados terem trazido as suas percepções. Neste artigo,tentar-se-á comprovar a hipótese sugerida pelos autores. Além disso, Kalfa e Taksa (2017) afirmam que a aceitação do managerialism nas IES torna-se evidente pela crescente ênfase na utilização de indicadores de desempenho.

Dessa forma, a relevância do estudo está caracterizada pela alteração de práticas gerenciais que vêm sendo empregadas nas instituições de ensino superior. A pesquisa quantitativa identifica na prática o que diversos autores apontam em seus artigos, por meio de observações/percepções. Dessa forma, por meio do empirismo, buscou-se a evidenciação de um fenômeno que vem ocorrendo nas instituições de ensino superior e destacada por autores (ADRIANO; RAMOS, 2015; ALMEIDA, 2012; BLASCHKE; FROST; HATTKE, 2014; BRUECKNER; HOLMES; PICK, 2017; KALFA; TAKSA, 2017; MEYER; MEYER JÚNIOR, 2013; MEYER JR.; PASCUCCI; MANGOLIN, 2012; ORR; ORR, 2016; PETERS, 2013; SANTIAGO; CARVALHO, 2012; VIEIRA; MENDONÇA NETO; ANTUNES, 2015; WILLNER, 2017).A contribuição do artigo para a ciência - e, por consequência, sua relevância - está na comprovação empírica do managerialism nas IES brasileiras.

\section{Managerialism nas IES do Brasil}

A retórica do managerialism no ensino superior está se consolidando firmemente no discurso dos gestores governamentais e tem sido divulgado institucionalmente. O managerialism é um importante suporte ideológico das novas políticas de gestão e pode ser classificado como uma narrativa de mudança estratégica (PETERS, 2013; SANTIAGO; CARVALHO, 2012).

O managerialism, na educação superior brasileira, é caracterizado por formas diferentes de combinação: financiamento, fornecimento, regulação e controle (CARVALHO, 2009; FALQUETO, FARIAS, 2013); sendo uma característica que tem definido as organizações. A partir disso, observa-se a utilização do modelo 
gerencial não só nas grandes empresas,como também no setor público, no não governamental e nas IES. Esse modelo gerencial foi construído a partir da ideologia do mercado e está focado na constante busca da eficiência e na avaliação de desempenho,sendo construído por um conjunto de ações práticas e de discursos que visam produzir um mundo onde é possível controlar os gestores e as tecnologias de gestão (VIEIRA; MENDONCA NETO; ANTUNES, 2015).

Percebe-se o managerialism no setor educacional, já que as instituições de ensino passaram a assumir modelos de gestão pautados no desempenho do docente e, implicitamente, na sua vigilância e controle (VIEIRA; MENDONCA NETO; ANTUNES, 2015).

Melo Filho et al. (2015) afirmam que a estratégia para ser bem-sucedida necessita da aplicação de princípios que apresentem consistência e de condições empresariais com modificação constante.Afirmam que pesquisara estratégia sob princípios gera a possibilidade de entender porque existem modelos de gestão mais adequados do que outros em determinadas situações.

As instituições de ensino superior vêm sofrendo pressões para rever a sua gestão e buscar formas mais eficientes e eficazes de atuação. Os motivos que levam a isto, são:1) as constantes mudanças na política educacional, 2) as flutuações na demanda por cursos e as renovadas necessidades, 3) as demandas do setor produtivo e 4) as expectativas dos alunos. Isto tem feito com que as instituições se lancem em busca de um gerenciamento estratégico que lhes permita melhor definição de objetivos, estabelecimento de prioridades, uso mais adequado dos recursos e, em especial, a materialização das estratégias. Um dos aspectos críticos da gestão universitária tem sido a prática de estratégias que permitam a esse tipo de organização alcançar o desempenho desejado e se manter competitiva no setor (MEYER JR.; PASCUCCl; MANGOLIN, 2012).

Marinho e Poffo (2016) afirmam que nas IES a qualidade tende a assumir função central por conta do crescimento do número de concorrentes, de cursos e de números de vagas ofertadas de modalidade presencial e a distância. Nesse sentido, o INEP cumprindo o seu papel de avaliar o ensino superior brasileiro, estará constantemente formulando os indicadores de qualidade, promovendo o que acredita ser melhoria contínua de um sistema de avaliação eficaz.

Os direitos de decisão e a informação em conjunto são aspectos cruciais para a maioria dos pesquisados no que se refere à execução eficaz da estratégia organizacional. Portanto, entende-se que os colaboradores necessitam de informações objetivas, claras e corretas, acrescidas de incentivos adequados aos seus interesses e alinhados aos da organização, e tudo isso acrescido da autoridade para agir tomando as decisões. A estrutura organizacional adequada a esse contexto tende a promover o alinhamento e a sinergia dos outros princípios (LIMA et al., 2013).

Para Almeida et al. (2016), existem poucas características em comum com o modelo clássico de gestão universitária quando comparado com o novo contexto do ensino superior no período pós 1995. Portanto, Meyer Jr., Pascucci e Mangolin (2012) verificaram a existência do que denominaram managerialism, ou seja, a implantação de ferramentas de gestão de empresas em IES, principalmente privadas. Pascuci et al. (2016) afirmam que diversas metodologias de gestão oriundas do mercado têm sido absorvidas pela universidade, tais como Planejamento Estratégico, Orçamento, Sistema ISO, entre outros.

Quando se fala em eficácia, eficiência, qualidade, desempenho, responsabilidade, remete-se a avaliação interna ao modelo de managerialism e cultura do desempenho, que implícita ou explicitamente vem sendo adotados nas Instituições de Ensino Superior no Brasil (BATISTA, 2016).

Conforme Meyer e Meyer Júnior (2013), percebe-se que as políticas e estratégias de gestão implantadas, oriundas do managerialism, tiveram seus maiores efeitos na melhoria do desempenho financeiro. Todavia, o desempenho de instituições educacionais é medido por variáveis qualitativas que escapam ao conteúdo das abordagens gerenciais empresariais, voltadas para sistemas racionais e mecanicistas. O desempenho é medido pelas transformações ocorridas nos alunos, na sua educação, na sua formação geral e profissional, nos seus valores, bem como nas mudanças comportamentais. No entanto, na área acadêmica, muitas das estratégias adotadas se mostraram ineficazes, não resultando na melhoria da qualidade da educação oferecida.Orr e Orr(2016) afirmam que o managerialism reduz a eficiência e a qualidade do ensino, pesquisa 
e administração acadêmica, bem como não consegue melhorar as universidades, ou avaliar com precisão o desempenho acadêmico.

Blaschke, Frost e Hattke (2014) indicam uma oposição entre a tradicional estrutura colegialista adotada pelas instituições de educação superior e o managerialism decorrente da aproximação das instituições universitárias com as práticas de gestão das empresas. As instituições de educação superior têm sido pressionadas para adoção de práticas do managerialism, que refletem na forma individualizada de gestão.

Em seu estudo, Santiago e Carvalho (2012) afirmam quea maioria dos acadêmicos apóia os valores acadêmicos tradicionais, como autonomia e colegialidade, e rejeita a governança universitária ou politécnica baseada na filosofia corporativa. Nesse mesmo sentido, Adriano e Ramos (2015) afirmam que, à medida que analisam as práticas da liderança no seu estudo de caso, verifica-se que o colegialismo é mais influente que o managerialism, porém, à medida que se diminui a perspectiva de análise, da instituição de educação superior para o Centro, o managerialism é mais influente que o colegialismo, refletindo em práticas de liderança mais individualizadas, muito embora alguns dos diretores entrevistados também fomentem a liderança distribuída em seus Centros.

Nesse mesmo sentido, Kalfa e Taksa (2017) afirmam que a aceitação do managerialism nas IES acarretou em uma cultura de desempenho, a qual se torna evidente pela crescente ênfase na utilização de indicadores de desempenho.

Para Willner (2017), o managerialismtem sido tradicionalmente explorado a partir de perspectivas organizacionais ou de gestão, e grande parte da pesquisa sobre o tema se concentrou em examinar a motivação por trás de organizações sem fins lucrativos que adotaram abordagens e práticas mais comumente encontradas no setor com fins lucrativos, e que enfatizam práticas relacionadas à eficiência, estratégia e competitividade, assim como um foco forte na gestão (BRUECKNER, HOLMES, PICK, 2017).

Dias Sobrinho (2015) afirma que as IES que se apegam mais em indicadores de origem empresarial tendem a dar mais atenção à sustentabilidade financeira do que à formação do conhecimento e qualidade científica.

\section{Metodologia da Pesquisa}

Na literatura, encontrou-se 106 (cento e seis) indicadores de avaliação de desempenho de IES, os quais foram agrupados em dois grupos. Os indicadores com origem na avaliação institucional do MEC e indicadores com origem em sistemas avaliativos oriundos de modelos empresariais. Conforme pode ser visto no apêndice 1, 55 (cinquenta e cinco) indicadores são oriundos do MEC e 51 (cinquenta e um) de empresas.

Após a análise dos indicadores coletados nos artigos sobre avaliação de desempenho em instituições de ensino superior, foi esboçado um modelo teórico preliminar, contendo os indicadores que constavam nos modelos encontrados na literatura. O modelo preliminar buscou enquadrar todos os indicadores possíveis encontrados em todos os outros modelos pesquisados. Todos os indicadores foram analisados individualmente e uma triagem foi feita para realizar as exclusões por repetição. A partir dessa depuração, o modelo preliminar foi composto por 106 (cento e seis) indicadores.

No questionário,os respondentes atribuíram notas entre zero e cinco (Escala Likert), sendo zero referente ao não se aplica, as notas um e dois indicadores não representativos, três um indicador mediano e quatro e cinco significando indicadores representativos da realidade.

Ao término do questionário foi inserida uma tabela que contempla uma explicação sobre cada indicador. Essa tabela tem a finalidade de auxiliar os respondentes sobre o que significa cada indicador e basilar os termos utilizados no questionário.

O pré-teste do questionário foi feito com diretores da universidade em que os pesquisadores trabalham. A ideia consistiu em verificar questões que justificassem alteração da redação, formato ou serem eliminadas da versão final. O questionário foi aplicado por meio eletrônico com o auxílio da ferramenta Google drive. Para a validação do questionário, foi utilizado a técnica de alfa de Cronbach, pois com essa técnica é possível estimar a confiabilidade do questionário aplicado em uma pesquisa. 
O alfa de Cronbach mede a correlação da respostas por meio da análise das respostas dadas, apresentando uma correlação média entre as perguntas. A correlação superior a 0,8 (zero vírgula oito) significa que o questionário é confiável. O coeficiente alfa é calculado a partir da variância dos itens individuais e da variância da soma dos itens de cada avaliador de todos os itens de um questionário que utilizem a mesma escala de medição (HORA; MONTEIRO; ARICA, 2010).

$\alpha=K /(K-1) \times\left(1-\sum V i / V t\right)(1)$

Onde:

$A=$ alfa de Cronbach

$\mathrm{K}=$ número de itens

$\mathrm{Vi}=$ variância de cada item

$\mathrm{Vt}=$ variância total

$\alpha=106 /(106-1) \times(1-134,68 / 4.255,55)=0,977(2)$

O público-alvo desta primeira parte da pesquisa foram dirigentes e integrantes das CPAs (Comissão Própria de Avaliação), os quais podem contribuir com informações relevantes sobre a avaliação de desempenho da instituição. A partir do cálculo para amostra de Barbetta (2007), para nível de confiança de 95\% e erro amostral de $8 \%$, a meta amostral dessa etapa do artigo foi de 123 (cento e vinte e três) respondentes.

Teve-se 124 (cento e vinte e quatro) respondentes de instituições privadas (59,68\%), seguidos de instituições públicas $(29,84 \%)$ e comunitárias $(10,48 \%)$. Os respondentes do questionário deveriam escolher uma das três categorias, isso porque não se pedia a identificação da instituição do respondente. Ressaltase que as IES foram excluídas da comparação.

Após a coleta dos dados feita por meio do questionário contendo 106 (cento e seis) indicadores, partiu-se para o teste estatístico de algumas hipóteses desta pesquisa.

- $\mathrm{HO}=$ A percepção de dirigentes e integrantes das CPAs (Comissão Própria de Avaliação)de IES públicas e privadas são iguais, ou seja, não existe managerialism;

Para testar a hipótese, utilizar-se-á da técnica estatística denominada teste t para grupos independentes. Esses testes se aplicam a planos amostrais em que se deseja comparar dois grupos independentes. No caso deste artigo, os grupos foram formados por indivíduos da mesma população que foram alocados a um dos dois tratamentos em estudo. Diferente do caso de dados pareados, esse teste não exige que as amostras tenham o mesmo tamanho (BARBETTA, 2007).

Uma das suposições do teste t é de que as variâncias dos dois grupos são iguais. Dessa forma, testou-se essa hipótese antes, por meio do teste de Levene. Posteriormente, a partir do resultado do teste, escolhe-se o resultado do teste t supondo variâncias iguais ou supondo variâncias diferentes. Quando as suposições paramétricas são atendidas, o teste t de Student para amostras independentes é mais adequado para comparação das médias dos grupos.

Para rejeitar ou aceitar as hipóteses, se utilizará o p-value (valor de p) como referência de comparação estatística. $\mathrm{O}$ valor de $\mathrm{p}$ é a probabilidade, quando $\mathrm{HO}$ é verdadeira, de observar uma amostra tão ou mais diferente/rara (na direção de $\mathrm{HA}$ ) do que a amostra que temos (não é uma suposição de risco). O valor de $p$ simplesmente descreve a "raridade" da amostra que se tem. Desta forma, se $p \leq \alpha$, a amostra é suficientemente rara para se rejeitar H0 (BARBETTA, 2007).

Foi utilizado o software Excel e SPSS para efetuar os cálculos de diferença de médias (teste t para grupos independentes) e testar a validade das duas hipóteses. Assim, se $\alpha<\mathrm{p}$-value, aceitamos a hipótese H0.

\section{Resultados}

Nesta seção, verificar-se-á a hipótese sobre a implantação de ferramentas de gestão de empresas em IES, principalmente privadas. Verificar-se-á, estatisticamente, se nas IES privadas os indicadores de 
ferramentas de avaliação de desempenho com origem nas empresas possuem relevância diferente do que nas IES públicas.

No quadro do apêndice 1estão expressas cinco colunas. Na primeira estão os indicadores constantes no questionário aplicado ao público-alvo. Na segunda está o valor calculado de $\mathrm{p}$ para testar $\mathrm{H} 0$. Na terceira coluna se apresenta o valor de alfa, que serve de parâmetro de comparação para testar $\mathrm{H} 0$. Na quarta coluna está descrito se existe diferença estatística nas respostas entre instituições de educação superior públicas e instituições de educação superior privadas. Na quinta coluna está escrita a origem do indicador testado.

Foram apresentados os 106 (cento e seis) indicadores evidenciados na literatura pesquisada e a verificação de existência de diferença de percepção acerca da importância do indicador para respondentes pertencentes às IES públicas ou privadas.

Verificou-se que $80 \%$ (oitenta por cento) dos indicadores de origem na avaliação institucional do MEC não possuem diferença estatística na percepção dos dois grupos. Os indicadores que apresentam diferença são: Existência de Comitê de ética em pesquisa; Procedimentos de avaliação dos processos de ensino-aprendizagem; Laboratórios didáticos especializados: serviços; Titulação do corpo docente do curso; Produção científica, cultural, artística ou tecnológica; Atividades de tutoria implantadas; Existência de Biotérios; Unidades hospitalares de ensino e complexo assistencial; Integração com o sistema local e regional de saúde e o SUS; e Existência de Laboratórios de habilidades.

Dos dez indicadores que possuem diferença de médias, quatro tem origem no questionário específico da área da saúde;um no questionário específico para $\mathrm{EaD}$, quatro no questionário do curso e um no questionário institucional.

Em 41\% (quarenta e um por cento) dos indicadores com origem em metodologias de avaliação de desempenho empresarial houve diferenças de percepção nos dois grupos. Esse percentual é mais do que o dobro do apresentado nos indicadores de origem na avaliação institucional do MEC.

Os indicadores que apresentam essa diferença são: Receita operacional líquida; Receita por disciplina; Margem de lucro; Índice de despesas administrativas; Índice de despesas administrativas por professor; Sustentabilidade financeira; Ponto de equilíbrio; Índice de inadimplência; Meta de qualidade corporativa; Desempenho corporativo dividido pela meta de qualidade; Desempenho operacional; Participação no mercado interno (\%); Prospecção de novos alunos; Despesas diretas do curso dividido por despesas administrativas; Número de turmas; Tempo de ciclo; Número de alunos por professor; Número de clientes internos; Número de alunos com desconto na mensalidade; Índice de alunos com desconto; e Rotatividade dos professores.

Em 32 (trinta e dois)indicadores se rejeitou H0, evidenciando a diferença estatística de médias entre a percepção da importância desses indicadores entre os grupos de respondentes de IES públicas e IES privadas. Dessa forma, evidenciando a existência do managerialism.

Destaca-se também que onze indicadores apresentaram $p$ entre 0,051 e 0,099, ficando dentro da análise unicaudal, a saber: Existência de laboratórios de ensino; Políticas institucionais no âmbito do curso; Número de professores; Integração com as redes públicas de ensino; Contexto educacional; Titulação e formação do corpo de tutores do curso; Laboratórios didáticos especializados; Responsabilidade docente pela supervisão da assistência médica; Titulação do corpo docente do curso - percentual de doutores; Plano de carreira docente; Relação docentes e tutores - presenciais e a distância - por estudante. Assim, se a $\mathrm{HO}$ fosse de que se dá menos importância para o indicador na IES pública, esses indicadores também apresentariam diferença na análise, confirmando ainda mais a existência de managerialism.

\section{Discussão}

A origem do managerialism nas IES brasileiras está na pressão em rever a gestão e encontrar formas eficazes de atuação. A operacionalização se dá pela visão mais competitiva da sua gestão, isso porque as IES estão inseridas em um contexto cada vez mais competitivo e que sofre com constantes transformações. Essa pressão externa faz com que os gestores das IES adotem modelos de gestão empresarial procurando um foco maior na produtividade e na busca de resultados econômico-financeiros (ADRIANO; RAMOS, 2015; 
ALMEIDA, 2012; BATISTA, 2016; MEYER; MEYER JÚNIOR, 2013; MEYER JR; PASCUCCI; MANGOLIN, 2012; PASCUCl et al., 2016; VIEIRA; MENDONÇA NETO; ANTUNES, 2015).

Diversos autores vêm explorando a realidade das IES brasileiras no tocante ao managerialism (ALMEIDA, 2012; MEYER JR; PASCUCCI; MANGOLIN, 2012; PASCUCI et al., 2016; VIEIRA; MENDONÇA NETO; ANTUNES, 2015), enfocando a existência principalmente em IES privadas. Também em estudo em outros países, tais como em Portugal (SANTIAGO; CARVALHO, 2012) e na Austrália(KALFA; TAKSA, 2017; ORR; ORR, 2016; PETERS, 2013), com enfoque no managerialism disseminado em todo o sistema educacional superior desses países.

Identificou-sena pesquisa quantitativa realizada a diferença estatística na percepção da importância de indicadores de desempenho. Dos cento e seis indicadores utilizados na pesquisa, quarenta e dois apresentam diferença na percepção entre as IES públicas e privadas. Em cinquenta e três deles as IES públicas valorizam menos os indicadores do que as IES privadas. Isto corrobora o que Meyer Jr, Pascucci e Mangolin (2012) indicaram em seu estudo teórico, em que apontam a existência demanagerialism em IES privadas brasileiras.

Ao considerar a utilização de indicadores como forma de avaliar a instituição, observamos que oitenta por cento dos indicadores de origem de avaliação do Ministério da Educação não apresenta diferença estatisticamente relevante na percepção dos gestores, o que pode indicar a existência de managerialism também em instituições sem fins lucrativos, tendo em vista as médias altas das respostas apresentadas. Isto pode ocorrer também pela existência de pressões regulatórias governamentais incisivas sobre o campo educacional do ensino superior. Este achado estatístico vai ao encontro de estudos internacionais, tais como os de Orr e Orr (2016); Brueckner, Holmes ePick (2017) e Willner (2017).

A preocupação de o managerialism estar sendo inserido na cultura organizacional das IES brasileiras é que, conforme diversos autores afirmam, o managerialisme seu apego demasiado em indicadores de desempenho reduzem a eficiência e a qualidade do ensino, da pesquisa e da administração acadêmica. Ele não consegue melhorar as universidades ou avaliar com precisão o desempenho acadêmico, pois as IES se atentam mais em sua sustentabilidade financeira do que na formação do conhecimento e qualidade científica(SOBRINHO, 2015; MEYER JR; PASCUCCI; MANGOLIN, 2012; O'BYRNE; BOND, 2014; ORR; ORR, 2016; PETERS, 2013; SANTIAGO; CARVALHO, 2012), bem como em estudos sobre a avaliação de desempenho de IES brasileiras (SILVA JUNIOR et al., 2014; SOBRINHO, 2003;LANGRAFE et al., 2009).

Este artigo limita-se às escolhas feitas pelos autores. Para os testes estatísticos foram utilizados os agrupamentos a partir dos respondentes. Como os agrupamentos não tiveram a mesma quantidade de respondentes, utilizou-se o teste t para amostras de tamanhos diferentes. Partiu-se para uma análise exploratória das hipóteses que são válidas para a amostra estudada.

\section{Conclusão}

O objetivo deste artigo consistia em "verificar, estatisticamente, se nas IES privadas os indicadores de avaliação de desempenho possuem relevância diferente do que nas IES públicas, tentando identificar a existência do managerialism.". Após a coleta dos dados, feita por meio do questionário contendo 106 (cento e seis) indicadores, testou-se HO como "A percepção de dirigentes e integrantes das CPAs (Comissão Própria de Avaliação)de IES públicas e privadas são iguais, ou seja, não existe managerialism". Assim, $80 \%$ dos indicadores de origem na avaliação institucional do MEC não possuem diferença estatística na percepção dos dois grupos, possivelmente por estarem expostos ao mesmo tipo de pressão institucional. Em $41 \%$ dos indicadores com origem em metodologias de avaliação de desempenho empresarial houve diferenças de percepção nos dois grupos. Esse percentual é mais do que o dobro do apresentado nos indicadores de origem na avaliação institucional do MEC. Em 29,91\% dos indicadores se rejeitou H0, evidenciando a diferença estatística de médias entre a percepção da importância desses indicadores entre os grupos de respondentes de IES públicas e IES privadas. Portanto, evidenciando a possibilidade de existência do managerialism. 
Observa-se a existência de managerialism nas IES brasileiras, principalmente as de cunho privado. Os indicadores de avaliação de IES com origem no MEC tiveram mais relevância, proporcionalmente, para as IES públicas do que para as privadas. Já os indicadores empresariais tiveram mais relevância para as IES privadas do que para as públicas. Conforme identificado na literatura, as IES têm sido pressionadas a reverem sua gestão e buscarem formas mais eficientes e eficazes de atuação por meio de uma visão mais competitiva e continuada da sua gestão, pois estão inseridas em um contexto competitivo e de grandes transformações. Assim, procuram se apoiar em modelos de gestão empresarial nas práticas gerenciais, buscando um foco maior na produtividade e na busca de resultados econômico-financeiros, o que pode acarretar em problemas na formação do conhecimento e qualidade científica.

Entende-se que o managerialism tende a distanciar as IES de seu papel social e educacional, pois foca em resultados. Todavia, cabe ressaltar que uma gestão eficaz pode ser considerada uma questão de sobrevivência neste contexto econômico, social e tecnológico.

Como qualquer trabalho na área de ciências sociais, este artigo limita-se às escolhas feitas pelo autor. Em termos metodológicos, além das limitações já expostas nos procedimentos metodológicos referentes à operacionalização desta pesquisa, cabe enfatizar a opção por compreender a avaliação de desempenho em IES no Brasil. Além disso, identifica a existência do managerialism sem verificar a percepção dos respondentes acerca dos benefícios e malefícios de sua adoção. Levantadas tais limitações, destaca-se que a pesquisa tal qual foi delineada e operacionalizada tornou viável que se respondessem às questões de pesquisa e se atingissem os objetivos propostos.

A partir das limitações expostas, sugere-se, primeiramente, que outros estudos possam encontrar estratégias de pesquisa que possam suprimi-las. Novas pesquisas poderão ser feitas para verificar a percepção dos respondentes acerca dos benefícios e malefícios de sua adoção. Outra sugestão seria verificar o papel do reitor como membro decisivo dos resultados da empresa e na adoção de práticas que levem ao managerialism.

Espera-se que os resultados aqui apresentados possam servir de ponto de partida para futuras pesquisas na área. Um conhecimento mais abrangente dos aspectos examinados aqui pode fornecer orientações importantes para os gestores sobre as novas formas de gestão, o que lhes permite enfrentar as mudanças dinâmicas do mercado atual sem que existam problemas na formação do conhecimento e qualidade científica.

\section{Referências}

ADRIANO, B. M.; RAMOS, F. Liderança em instituições de ensino superior: o caso de uma Universidade Comunitária do Estado de Santa Catarina, Brasil. Espacios. [S.I], v. 36, n. 17, p. E-1, 2015. Disponível em: <http://www.revistaespacios.com/a15v36n17/153617E1.html>. Acesso em: 22 dez. 2016.

ALMEIDA, D. R. Gerencialismo e transformações no ensino superior federal: uma análise à luz da experiência UFBA. In: ENCONTRO DA ANPAD, 36., 2012, Rio de Janeiro, Anais..., Rio de Janeiro: ANPAD, 2012. p. 1-16. .Disponível em: <http://www.anpad.org.br/admin/pdf/2012_APB507.pdf>. Acesso em: 03 nov. 2016.

ALMEIDA, D. R.et al. Gerencialismo: efeitos no modelo de gestão de uma IFES. In: COLÓQUIO INTERNACIONAL SOBRE GESTÃO UNIVERSITÁRIA NA AMÉRICA DO SUL, 16., 2016, Arequipa, Peru. Anais... Arequipa, Peru: CIGU, 2016. p. 1-15. Disponível em: <https://repositorio.ufsc.br/ handle/123456789/171092>. Aceso em: 03 nov. 2016.

BARBETTA, P. A. Estatística aplicada às ciências sociais. Florianópolis: Ed. da UFSC, 2007.

BATISTA, M.E. Autoavaliação institucional: instrumento de gestão para promoção da qualidade ou de produção da cultura da performatividade? In: CONGRESSO IBERO-AMERICANO EM INVESTIGAÇÃO QUALITATIVA, 5, 2016, Porto, Anais...Porto: Atas CIAIQ, 2016. p. 817-822. Disponível em: <http:// proceedings.ciaiq.org/index.php/ciaiq2016/article/viewFile/674/662>. Acesso em: 03 nov. 2017. 
BLASCHKE, S.; FROST, J.; HATTKE, F. Towards a micro foundation of leadership, governance, and management in universities. HigherEducation.,[S.I], v. 68, n. 5, p. 711-732, 2014. Disponível em: <http:// download.springer.c34444444444om/>. Acesso em: 22 dez. 2016.

BRUECKNER, HOLMES, PICK. Out of sight: volunteering in remote locations in Western Australia in the shadow of managerialism. Third Sector Review, [S.I], v. 23, n. 1, p. 29-49, 2017.

CARVALHO, E. J. G. Reestruturação produtiva, reforma da administração do estado e gestão da educação. Educação e Sociedade, Campinas, v. 30, n. 109, p. 1139-1166, set./dez. 2009.

CRUZ, A. G.; PAULA, M. F. C. O setor privado-mercantil de educação superior no Brasil e a educação a distância. Germinal: marxismo e educação em debate. Salvador, v. 7, n. 2, p. 242-251, dez. 2015.

FALQUETO, J. M. Z.; FARIAS, J. S. A trajetória e a funcionalidade da universidade pública brasileira. Revista GUAL, Florianópolis, v. 6, n. 1, p. 22-41, jan.2013.

GEIGER, R. The private alternative in higher education. European Journal of Education, [S.I], v. 20, n. 4, p. 385-398, 1985.

GOERGEN, P. Educação superior na perspectiva do sistema e do plano nacional de educação. Educ. Soc., Campinas, v. 31, n. 112, p. 895-917, jul./set. 2010.

HORA, H. R. M.; MONTEIRO, G. T. R.; ARICA, J. Confiabilidade em questionários para qualidade: um estudo com o Coeficiente Alfa de Cronbach. Produto\&Produção, [S.I], v. 11, n. 2, p. 85-103, jun. 2010.

KALFA, S.; TAKSA, L. Employability, managerialism, and performativity in higher education: a relational perspective. Higher Education., [S.I], v. 74, n. 4, p. 687-699, Oct. 2017.

LANGRAFE, T. F. et al. Grupos estratégicos: um estudo dos cursos de graduação em Administração na cidade de São Paulo. RIAE - Revista Ibero-Americana de Estratégia, São Paulo, v. 8, n. 1, p. 78-101, jan./jun. 2009.

LIMA, M. A.et al. Autoavaliação de instituições de educação superior: exame de dificuldades organizacionais e gerenciais. Revista Electrónica de Investigación y Docencia (REID), [S.I], v. 10, p. 21-42, Jul. 2013.

MARINHO, S. V.; POFFO, G. D. Diagnóstico da qualidade em uma IES: a percepção da comunidade acadêmica. Avaliação, Campinas, SP, v. 21, n. 2, p. 455-477, 2016.

MELO FILHO, L. et al. Abordagem estratégica de Roadmapping na geração de diretrizes de inovação para firmas de um conglomerado industrial. Revista Ibero-Americana de Estratégia, [S.I], v. 14, n. 3, p. 1-26, jul/set. 2015. Disponível em: <http://www.revistaiberoamericana.org/ojs/index.php/ibero/article/ view/2138/pdf >. Acesso em: 03 nov. 2016.

MEYER, J. W.; ROWAN, B. Institutionalized organizations: formal structure as myth and ceremony. American Journal of Sociology.,[S.I], v. 83, v. 2, p. 340-363, 1977.

MEYER, B.; MEYER JUNIOR, V. Managerialism na gestão universitária: uma análise de suas manifestações em uma instituição empresarial. Revista GUAL, Florianópolis, v. 6, n. 3, p. 1-20, set. 2013. Disponível em: <https://periodicos.ufsc.br/index.php/gual/article/view/19834535.2013v6n3p1/25418>. Acesso em: 04 nov. 2016.

MEYER, JR, V.; PASCUCCI, L.; MANGOLIN, L. Gestão estratégica: um exame de práticas em universidades privadas. Rev. Adm. Pública, Rio de Janeiro, v. 46, n. 1, jan./fev. 2012.

O'BYRNE, D.; BOND, C. Back to the future: the idea of a university revisited. Journal of Higher Education Policy and Management, [S,I], v. 36, n. 6, p.571-584, 2014.

ORR, Y.; ORR, R. The Death of Socrates: Managerialism, Metrics and Bureaucratisation in Universities. Australian Universities' Review, [S.I], v. 58, n. 2, p. 15-25, 2016. 
PASCUCI, L et al. Managerialismna gestão universitária: implicações do planejamento estratégico segundo a percepção de gestores de uma universidade pública. Revista GUAL, Florianópolis, v. 9, n. 1, p. 37-59, jan. 2016. Disponível em: <https://periodicos.ufsc.br/index.php/gual/article/view/19834535.2016v9n1p37>. Acessoem: 04 nov. 2016.

PETERS, M. A. Managerialism and the neoliberal university: prospects for new forms of 'open management' in higher education. Contemporary Readings in Law and Social Justice, [S.I], v. 5, n. 1, p. 11-26, 2013.

SANTIAGO; R.; CARVALHO, T. Managerialismrhetorics in portuguese highereducation. Minerva. [S.I],v. 50, n. 4, p. 511-532, 2012.

SILVA JUNIOR, A. et al. Políticas públicas para a educação superior: a avaliação, a regulação e a supervisão de IES privadas em debate. Ensaio: aval. pol.públ. Educ., Rio de Janeiro, v. 22, n. 82, p. 215-240, jan./mar. 2014.

DIAS SOBRINHO, J. Avaliação da educação superior regulação e emancipação. Avaliação, Campinas, SP, v. 8, n. 2, p. 31-47, 2003.

Universidade fraturada: reflexões sobre conhecimento e responsabilidade social. Avaliação., São Paulo, v. 20, n. 3, p. 581-601, 2015. Disponível em: <http://www.scielo.br/pdf/aval/v20n3/1414-4077aval-20-03-00581.pdf>. Acesso em: 22 dez. 2016.

VIEIRA, A.M.; MENDONCA NETO, O. R.; ANTUNES, M. T. P. Aspectos da resistência na atividade docente. Educ. Pesqui., São Paulo, v. 41, n. 3, p.743-756, jul./set. 2015. Disponível em: <http://www. scielo.br/pdf/ep/v41n3/1517-9702-ep-s1517-97022015051679.pdf >. Acesso em: 22 dez. 2016.

WILLNER, L. The conflict is in the values: understanding the emergence and operationalization of managerialism in social justice nonprofit organizations.2017. 163f.Dissertação (Mestrado em Philosophy).= UNIVERSITY OF CALIFORNIA, Los Angeles, 2017. 
Apêndice 1 - Cálculo da existência de managerialism por meio dos indicadores.

\begin{tabular}{|c|c|c|c|c|}
\hline \multirow[b]{2}{*}{ Indicador } & \multicolumn{4}{|c|}{ Existência demanagerialism } \\
\hline & $\begin{array}{l}\mathrm{P}(\mathrm{T}<=\mathrm{t}) \text { bi- } \\
\text { caudal }\end{array}$ & alfa & $\begin{array}{c}\text { Estatisticamente } \\
\text { é comprovada a } \\
\text { diferença de média? } \\
(\mathrm{P}(\mathrm{T}<=\mathrm{t})<\mathrm{a})\end{array}$ & $\begin{array}{c}\text { Indicadores } \\
\text { com origem nas } \\
\text { empresas? }\end{array}$ \\
\hline \multicolumn{5}{|l|}{ QUESTIONÁRIO INSTITUCIONAL } \\
\hline Receita operacional líquida & 1,9E-06 & 0,05 & Sim & Sim \\
\hline Receita por disciplina & $1,21 \mathrm{E}-06$ & 0,05 & Sim & Sim \\
\hline Margem de lucro & $2,91 \mathrm{E}-11$ & 0,05 & Sim & Sim \\
\hline Índice de despesas administrativas & 0,001596 & 0,05 & Sim & Sim \\
\hline $\begin{array}{l}\text { Índice de despesas administrativas por } \\
\text { professor }\end{array}$ & 0,001181 & 0,05 & Sim & Sim \\
\hline Custos anuais por aluno & 0,429403 & 0,05 & Não & Sim \\
\hline Custos diretos por aluno & 0,291403 & 0,05 & Não & Sim \\
\hline $\begin{array}{l}\text { Despesas com o desenvolvimento de } \\
\text { competências por professor }\end{array}$ & 0,437105 & 0,05 & Não & Sim \\
\hline Investimentos & 0,159757 & 0,05 & Não & Sim \\
\hline Investimento em TI & 0,134622 & 0,05 & Não & Sim \\
\hline Investimento no suporte de $\mathrm{TI}$ aos alunos & 0,469075 & 0,05 & Não & Sim \\
\hline Investimento no treinamento de alunos & 0,114841 & 0,05 & Não & Sim \\
\hline Sustentabilidade financeira & $1,64 \mathrm{E}-05$ & 0,05 & Sim & Sim \\
\hline Ponto de equilíbrio & $7,75 \mathrm{E}-07$ & 0,05 & Sim & Sim \\
\hline Índice de inadimplência & $2,24 \mathrm{E}-14$ & 0,05 & Sim & Sim \\
\hline Meta de qualidade corporativa & 0,000273 & 0,05 & Sim & Sim \\
\hline $\begin{array}{l}\text { Desempenho corporativo dividido pela } \\
\text { meta de qualidade }\end{array}$ & 0,000596 & 0,05 & Sim & Sim \\
\hline $\begin{array}{l}\text { Espaço de trabalho para coordenação do } \\
\text { curso e serviços acadêmicos }\end{array}$ & 0,467534 & 0,05 & Não & Avaliação MEC \\
\hline Existência de protocolos de experimentos & 0,179043 & 0,05 & Não & Avaliação MEC \\
\hline $\begin{array}{l}\text { Existência de Comitê de ética em } \\
\text { pesquisa }\end{array}$ & 0,000291 & 0,05 & Sim & Avaliação MEC \\
\hline Controle da produção & 0,76254 & 0,05 & Não & Sim \\
\hline Desempenho operacional & 0,005043 & 0,05 & Sim & Sim \\
\hline Desenvolvimento de novos produtos & 0,608872 & 0,05 & Não & Sim \\
\hline Instalações físicas & 0,68743 & 0,05 & Não & Sim \\
\hline Gestão ambiental & 0,428001 & 0,05 & Não & Sim \\
\hline Organização e cultura & 0,488804 & 0,05 & Não & Sim \\
\hline Planejamento da produção & 0,228316 & 0,05 & Não & Sim \\
\hline Programação da produção & 0,209745 & 0,05 & Não & Sim \\
\hline Qualidade & 0,922376 & 0,05 & Não & Sim \\
\hline Saúde e segurança & 0,42767 & 0,05 & Não & Sim \\
\hline Tecnologia & 0,495851 & 0,05 & Não & Sim \\
\hline $\begin{array}{l}\text { Padronização das informações e dos } \\
\text { sistemas }\end{array}$ & 0,867891 & 0,05 & Não & Sim \\
\hline Plano de carreira docente & 0,078332 & 0,05 & Não & Sim \\
\hline Participação no mercado interno (\%) & 8,83E-09 & 0,05 & Sim & Sim \\
\hline Contexto educacional & 0,06176 & 0,05 & Não & Avaliação MEC \\
\hline $\begin{array}{l}\text { Integração com as redes públicas de } \\
\text { ensino }\end{array}$ & 0,060977 & 0,05 & Não & Avaliação MEC \\
\hline Prospecção de novos alunos & 0,000265 & 0,05 & Sim & Sim \\
\hline \multicolumn{5}{|l|}{ QUESTIONÁRIO CURSO } \\
\hline $\begin{array}{l}\text { Despesas diretas do curso dividido por } \\
\text { despesas administrativas }\end{array}$ & 0,002165 & 0,05 & Sim & Sim \\
\hline Número de turmas & 0,045574 & 0,05 & Sim & Sim \\
\hline
\end{tabular}




\begin{tabular}{|c|c|c|c|c|}
\hline Salas de aula & 0,72151 & 0,05 & Não & Avaliação MEC \\
\hline Tempo de ciclo & 0,821353 & 0,05 & Sim & Sim \\
\hline Políticas institucionais no âmbito do curso & 0,055782 & 0,05 & Não & Avaliação MEC \\
\hline Objetivos do curso & 0,31864 & 0,05 & Não & Avaliação MEC \\
\hline $\begin{array}{l}\text { Ações decorrentes dos processos de } \\
\text { avaliação do curso }\end{array}$ & 0,863085 & 0,05 & Não & Avaliação MEC \\
\hline $\begin{array}{l}\text { Utilização de tecnologias de informação } \\
\text { e comunicação no processo ensino- } \\
\text { aprendizagem }\end{array}$ & 0,73981 & 0,05 & Não & Avaliação MEC \\
\hline Estrutura curricular & 0,605922 & 0,05 & Não & Avaliação MEC \\
\hline Conteúdos curriculares & 0,639061 & 0,05 & Não & Avaliação MEC \\
\hline Metodologia das atividades pedagógicas & 1,00 & 0,05 & Não & Avaliação MEC \\
\hline $\begin{array}{l}\text { Estágio curricular supervisionado } \\
\text { regulamentado }\end{array}$ & 0,277012 & 0,05 & Não & Avaliação MEC \\
\hline $\begin{array}{l}\text { Atividades complementares } \\
\text { regulamentadas }\end{array}$ & 0,378812 & 0,05 & Não & Avaliação MEC \\
\hline $\begin{array}{l}\text { Trabalho de conclusão de curso (TCC) } \\
\text { regulamentado }\end{array}$ & 0,446492 & 0,05 & Não & Avaliação MEC \\
\hline \begin{tabular}{|l|} 
Procedimentos de avaliação dos \\
processos de ensino-aprendizagem
\end{tabular} & 0,039715 & 0,05 & Sim & Avaliação MEC \\
\hline Atuação do Núcleo Docente Estruturante & 0,925327 & 0,05 & Não & Avaliação MEC \\
\hline Número de alunos por professor & 0,02074 & 0,05 & Sim & Sim \\
\hline $\begin{array}{l}\text { Funcionamento do colegiado de curso ou } \\
\text { equivalente }\end{array}$ & 0,197642 & 0,05 & Não & Avaliação MEC \\
\hline $\begin{array}{l}\text { Núcleo de apoio pedagógico e } \\
\text { experiência docente }\end{array}$ & 0,321091 & 0,05 & Não & Avaliação MEC \\
\hline Disponibilidade da bibliografia básica & 0,452795 & 0,05 & Não & Avaliação MEC \\
\hline Acesso a bibliografia complementar & 0,135214 & 0,05 & Não & Avaliação MEC \\
\hline Acesso a periódicos especializados & 0,105726 & 0,05 & Não & Avaliação MEC \\
\hline Laboratórios didáticos especializados & 0,063661 & 0,05 & Não & Avaliação MEC \\
\hline $\begin{array}{l}\text { Laboratórios didáticos especializados: } \\
\text { serviços }\end{array}$ & 0,036843 & 0,05 & Sim & Avaliação MEC \\
\hline Qualificação continuada dos professores & 0,280732 & 0,05 & Não & Sim \\
\hline $\begin{array}{l}\text { Acesso dos alunos a equipamentos de } \\
\text { informática }\end{array}$ & 1,00 & 0,05 & Não & Avaliação MEC \\
\hline Perfil profissional do egresso & 0,678983 & 0,05 & Não & Avaliação MEC \\
\hline Número de alunos & 0,874944 & 0,05 & Não & Sim \\
\hline Número de clientes internos & 1,4E-05 & 0,05 & Sim & Sim \\
\hline $\begin{array}{l}\text { Número de alunos com desconto na } \\
\text { mensalidade }\end{array}$ & 7,17E-16 & 0,05 & Sim & Sim \\
\hline Índice de alunos com desconto & $1,34 \mathrm{E}-17$ & 0,05 & Sim & Sim \\
\hline Apoio ao discente & 0,469993 & 0,05 & Não & Avaliação MEC \\
\hline Satisfação dos alunos & 0,391547 & 0,05 & Não & Sim \\
\hline Retenção de alunos & 0,751928 & 0,05 & Não & Sim \\
\hline Índice de satisfação dos professores & 0,219876 & 0,05 & Não & Sim \\
\hline Número de professores & 0,059224 & 0,05 & Não & $\operatorname{Sim}$ \\
\hline Rotatividade dos professores & 0,007657 & 0,05 & Sim & Sim \\
\hline $\begin{array}{l}\text { Número médio de anos de serviços com a } \\
\text { universidade }\end{array}$ & 0,177317 & 0,05 & Não & Sim \\
\hline $\begin{array}{l}\text { Número de vagas correspondente ao } \\
\text { número de docentes }\end{array}$ & 0,129211 & 0,05 & Não & Sim \\
\hline $\begin{array}{l}\text { Gabinetes de trabalho para professores } \\
\text { Tempo Integral - TI }\end{array}$ & 0,147471 & 0,05 & Não & Avaliação MEC \\
\hline Sala de professores & 0,867991 & 0,05 & Não & Avaliação MEC \\
\hline Atuação do (a) coordenador (a) & 0,565289 & 0,05 & Não & Avaliação MEC \\
\hline
\end{tabular}




\begin{tabular}{|c|c|c|c|c|}
\hline $\begin{array}{l}\text { Regime de trabalho do (a) coordenador } \\
\text { (a) do curso }\end{array}$ & 0,6465 & 0,05 & Não & Avaliação MEC \\
\hline $\begin{array}{l}\text { Experiência profissional, de magistério } \\
\text { superior e de gestão acadêmica do (a) } \\
\text { coordenador (a) }\end{array}$ & 0,737583 & 0,05 & Não & Avaliação MEC \\
\hline Carga horária de coordenação de curso & 0,707736 & 0,05 & Não & Avaliação MEC \\
\hline Titulação do corpo docente do curso & 0,036345 & 0,05 & Sim & Avaliação MEC \\
\hline $\begin{array}{l}\text { Titulação do corpo docente do curso - } \\
\text { percentual de doutores }\end{array}$ & 0,070839 & 0,05 & Não & Avaliação MEC \\
\hline $\begin{array}{l}\text { Regime de trabalho do corpo docente do } \\
\text { curso }\end{array}$ & 0,25675 & 0,05 & Não & Avaliação MEC \\
\hline Experiência profissional do corpo docente & 0,496196 & 0,05 & Não & Avaliação MEC \\
\hline $\begin{array}{l}\text { Experiência no exercício da docência na } \\
\text { educação básica }\end{array}$ & 0,639783 & 0,05 & Não & Avaliação MEC \\
\hline $\begin{array}{l}\text { Experiência de magistério superior do } \\
\text { corpo docente }\end{array}$ & 0,635352 & 0,05 & Não & Avaliação MEC \\
\hline $\begin{array}{l}\text { Produção científica, cultural, artística ou } \\
\text { tecnológica }\end{array}$ & 0,046906 & 0,05 & $\operatorname{Sim}$ & Avaliação MEC \\
\hline Número de alunos relativos & 0,210392 & 0,05 & Não & Sim \\
\hline \multicolumn{5}{|l|}{ QUESTIONÁRIO EAD } \\
\hline Material didático institucional & 0,306277 & 0,05 & Não & Sim \\
\hline $\begin{array}{l}\text { Sistema de controle de produção e } \\
\text { distribuição de material didático }\end{array}$ & 0,843665 & 0,05 & Não & Sim \\
\hline Atividades de tutoria implantadas & 0,016893 & 0,05 & Sim & Avaliação MEC \\
\hline $\begin{array}{l}\text { Mecanismos de interação entre docentes, } \\
\text { tutores e estudantes }\end{array}$ & 0,131402 & 0,05 & Não & Avaliação MEC \\
\hline $\begin{array}{l}\text { Titulação e formação do corpo de tutores } \\
\text { do curso }\end{array}$ & 0,062923 & 0,05 & Não & Avaliação MEC \\
\hline $\begin{array}{l}\text { Experiência do corpo de tutores em } \\
\text { educação a distância }\end{array}$ & 0,029063 & 0,05 & Não & Avaliação MEC \\
\hline $\begin{array}{l}\text { Relação docentes e tutores - presenciais } \\
\text { e a distância - por estudante }\end{array}$ & 0,080608 & 0,05 & Não & Avaliação MEC \\
\hline \multicolumn{5}{|l|}{ QUESTIONÁRIO ÁREA DA SAÚDE } \\
\hline Existência de biotérios & 0,016032 & 0,05 & Sim & Avaliação MEC \\
\hline $\begin{array}{l}\text { Unidades hospitalares de ensino e } \\
\text { complexo assistencial }\end{array}$ & 0,01561 & 0,05 & $\operatorname{Sim}$ & Avaliação MEC \\
\hline $\begin{array}{l}\text { Responsabilidade docente pela } \\
\text { supervisão da assistência médica }\end{array}$ & 0,068721 & 0,05 & Não & Avaliação MEC \\
\hline $\begin{array}{l}\text { Integração com o sistema local e regional } \\
\text { de saúde e o SUS }\end{array}$ & 0,042292 & 0,05 & $\operatorname{Sim}$ & Avaliação MEC \\
\hline Existência de Laboratórios de ensino & 0,055659 & 0,05 & Não & Avaliação MEC \\
\hline Existência de Laboratórios de habilidades & 0,041942 & 0,05 & Sim & Avaliação MEC \\
\hline Sistema de referência e contrarreferência & 0,125258 & 0,05 & Não & Avaliação MEC \\
\hline \multicolumn{5}{|l|}{ QUESTIONÁRIO DIREITO } \\
\hline $\begin{array}{l}\text { Núcleo de Práticas Jurídicas: atividades } \\
\text { básicas }\end{array}$ & 0,953528 & 0,05 & Não & Avaliação MEC \\
\hline $\begin{array}{l}\text { Núcleo de Práticas Jurídicas: atividades } \\
\text { de arbitragem, negociação e mediação }\end{array}$ & 0,838646 & 0,05 & Não & Avaliação MEC \\
\hline
\end{tabular}

Submetido em: 30/10/17

Aprovado em: 06/03/18 